\title{
“ARQUEOLOGIA” DAS APRENDIZAGENS NO ALANDROAL: A FOTOGRAFIA DE UMA DÉCADA DE QUALIFICAÇÃO ${ }^{1}$
}

\author{
Bravo Nico \\ Lurdes Pratas Nico \\ Antónia Tobias \\ Centro de Investigação em Educação e Psicologia da Universidade de Évora
}

Palavras-Chave: Educação Formal, Educação não-formal, Educação e Desenvolvimento Local, Qualificação

$\mathrm{Na}$ presente comunicação, serão apresentados os resultados, já disponíveis, decorrentes da concretização do projecto de investigação "Arqueologia" das Aprendizagens no Alandroal promovido pelo Centro de Investigação em Educação e Psicologia da Universidade de Évora e financiado pela Fundação para a Ciência e a Tecnologia (FCT).

O projecto assume, como principal finalidade, a identificação e caracterização de todas as aprendizagens disponibilizadas e concretizadas no território do município do Alandroal (concelho alentejano do Distrito de Évora, com seis freguesias e aproximadamente 6200 indivíduos adultos recenseados nos cadernos eleitorais), no período 1997-2007.

Tendo-se iniciado com um procedimento de cartografia institucional e, em cada instituição identificada, do mapeamento de todas as aprendizagens disponibilizadas, o projecto encontra-se, presentemente, a iniciar o procedimento de sinalização e consequente caracterização de todas as aprendizagens protagonizadas pelos indivíduos residentes no território.

Destes dois momentos de pesquisa, resultará uma fotografia bastante objectiva do que foi a realidade da qualificação no território em causa, concretizada através de um conjunto heterogéneo de aprendizagens realizadas em contextos diferentes natureza.

\footnotetext{
${ }^{1}$ Projecto promovido pelo Centro de Investigação em Educação e Psicologia da Universidade de Évora e financiado pela FCT (PTDC/CED/81388/2006)
} 